\title{
Outcomes of oblique lateral interbody fusion for degenerative lumbar disease in patients under or over 65 years of age
}

\author{
Chengzhen Jin, Milin S. Jaiswal, Sin-Soo Jeun, Kyeong-Sik Ryu, Jung-Woo Hur and Jin-Sung Kim
}

\begin{abstract}
Background: Oblique lateral interbody fusion (OLIF) offers the solution to problems of anterior lumbar interbody fusion (ALIF) and lateral lumbar interbody fusion (LLIF). However, OLIF technique for degenerative spinal diseases of elderly patients has been rarely reported. The objective of this study was to determine the clinical and radiological results of OLIF technique for degenerative spinal diseases in patients under or over 65 years of age.
\end{abstract}

Methods: Sixty-three patients who underwent OLIF procedure were enrolled, including 29 patients who were less than 65 years of age and 34 patients who were over 65 years of age. Fusion rate, change of disc height and lumbar lordotic angle, Numeric Rating Scale (NRS), return to daily activity, patient's satisfaction rate (PSR), and Oswestry disability index (ODI) were used to assess clinical and functional outcomes.

Results: The mean NRS scores for back and leg pain decreased, respectively, from 4.6 and 5.9 to 2.3 and 1.8 in the group A (less than 65 years) and from 4.5 and 6.8 to 2.6 and 2.2 in the group B (over 65 years) at the final follow-up period. The mean ODI scores improved from 48.4 to $24.0 \%$ in the group A and from 46.5 to $25.2 \%$ in the group B at the final follow-up period. In both groups, the NRS and ODI scores significantly changed preoperatively to postoperatively $(p<0.001)$. However, statistical analysis yielded no significant difference in postoperative NRS/ODI scores between two groups. In both groups, the changes in the disc height, segmental lordosis, and fusion rate between the preoperative and postoperative periods were significant. The amount of change between preoperative and postoperative disc height, segmental lordosis, and whole lumbar lordosis demonstrated significant intergroup differences $(p<0.05)$. Overall perioperative complications occurred in 8 of $29(27.6 \%)$ patients in the group A and in 10 of 34 (29.4\%) patients in the group B. In both groups, the major complication incidence was 0 and 3\%, respectively.

Conclusion: Although there was the slightly high incidence of complication associated with high rate of comorbidities in elderly patients, OLIF for degenerative lumbar diseases in elderly patients showed favorable clinical and radiological outcomes.

Keywords: Oblique lateral interbody fusion, Co-morbidity, Complication, Elderly patients, Degenerative

\section{Background}

For years, lumbar interbody fusion has been used as a powerful surgical tool for various pathologies of the lumbar spine including degenerative disc disease (DDD), spondylolisthesis, disc herniation, and deformity $[1,2]$. Conventional anterior lumbar interbody fusion (ALIF) [3] and posterior/transforaminal lumbar interbody fusion

\footnotetext{
* Correspondence: md1david@catholic.ac.kr; mdlukekim@gmail.com Spine Center, Department of Neurosurgery, Seoul St. Mary's Hospital, College of Medicine, The Catholic University of Korea, Seoul, South Korea, 222 Banpo-daero Seocho-gu, Seoul 06591, Republic of Korea
}

(PLIF/TLIF) [4-6] techniques have given excellent fusion and clinical results. However, they have their own restrictions and disadvantages. Surgical approaches have also been improved with new innovations including the introduction of lateral lumbar interbody fusion (LLIF) [7-9], a lateral approach between the retroperitoneal space and psoas muscle to allow access to the lumbar spine. To decrease surgical trauma, reduce operative bleeding and infection incidence, and reduce hospital stay, minimally invasive spinal (MIS) surgical approaches and techniques are more and more refined since their 
first introduction [10]. To counter approach-related hurdles of ALIF and LLIF, oblique lateral interbody fusion (OLIF) has been proposed as a solution to access lumbar disc space by taking advantages of the surgical space between the aorta and psoas muscle [11, 12]. With better understanding and refinement of MIS surgical techniques, tides are turning from traditional PLIF/TLIF to MIS-TLIF and traditional ALIF/LLIF to OLIF.

Although clinical outcomes and complications of various lumbar interbody fusions have been assessed in many studies [13, 14], OLIF technique for the degenerative spinal disease of elderly patients has been rarely reported. Therefore, the objective of this study was to determine the clinical and radiological results of OLIF technique in patients under and over 65 years of age and compare the differences between the two groups.

\section{Methods}

\section{Patient population}

From June 2013 to May 2016, 86 patients who underwent OLIF procedure for the degenerative spinal disease were enrolled in this study. OLIF was performed by a single surgeon. Among these 86 patients, patients who had neoplasm, infectious disease, trauma, more than three-level fusion surgeries, deformity of more than $20^{\circ}$ on coronal plane, or follow-up period of fewer than 1 year were excluded. Patients who suffered from low back pain and/or leg pain with neurogenic intermittent claudication and progressive neurological deficit and confirmed to have lumbar stenosis, spondylolisthesis, and herniated nucleus pulposus (HNP) by radiological examinations were included. Before surgical intervention was advised, conservative treatment for over 2 months failed in these patients. After excluding 23 patients who met the exclusion criteria, a total of 63 patients who met the inclusion criteria were finally included in this study, including 29 (46.03\%) patients who were less than 65 years of age (group A) and 34 (53.97\%) patients who were over 65 years of age (group B). Of the 63 patients, 43 (68.3\%) had no previous history of lumbar surgery, 11 (17.4\%) had adjacent segment disease (ASD) with the previous history of lumbar fusion surgery, and 9 (14.3\%) had previous posterior lumbar decompression without stabilization surgery. Medical records of these 63 patients were reviewed to obtain demographic data, primary diagnosis, and the length of hospital stay, preoperative co-morbidities, segmental fusion status, and postoperative complications. This study was approved by institutional review board (IRB) of our institution. Informed written consents were obtained from all the subjects participating in the study.

\section{Operative technique}

Patient was placed in a right-sided lateral decubitus position. Under fluoroscopic control, anatomical surface of the disc in true lateral view was marked on the skin. Standard preoperative preparation of surgical field was done. For single-level fusion, $2.5-3.0-\mathrm{cm}$ skin incision was made centered in the projection of the target segment and parallel to external oblique muscle fibers (Fig. 1). External oblique muscle, internal oblique muscle, and transverse abdominal muscle were dissected along the direction of their fibers with a blunt musclesplitting technique. Retroperitoneal space was accessed by blunt dissection along the retroperitoneal fat tissue. The peritoneal sac was mobilized anteriorly. The psoas muscle was dissected with the index finger and retracted posteriorly. The targeted disc space was exposed and tubular retractor system was docked (Fig. 2). Special attention was given to the genitofemoral nerve, the sympathetic chain, and segmental blood vessels. In multi-level cases, the incision was enlarged up to $4.0-6.0 \mathrm{~cm}$ or multiple skin incisions of $2.5-3.0 \mathrm{~cm}$ per level were made. Imaging guidance (fluoroscopy) was used to confirm the correct level. After discectomy, vertebral endplates were prepared and the subchondral bone was exposed. To achieve interbody fusion, cage packed with demineralized bone matrix (DBM) or harvests of iliac bone was inserted (Fig. 3). After the anterolateral procedure, posterior lumbar stabilization was performed with percutaneous pedicle screw fixation or open pedicle screw fixation (Fig. 4).

\section{Assessment of clinical outcomes}

Co-morbidities were classified as cardiovascular, cerebrovascular, pulmonary, urologic, gastrointestinal, endocrinological, hepatobiliary, and history of cancer. Complications were classified as surgical approach-related complications and surgical approach-non-related complications. Clinical results were evaluated according to Numeric Rating Scale (NRS) for back and leg pain and Oswestry disability index

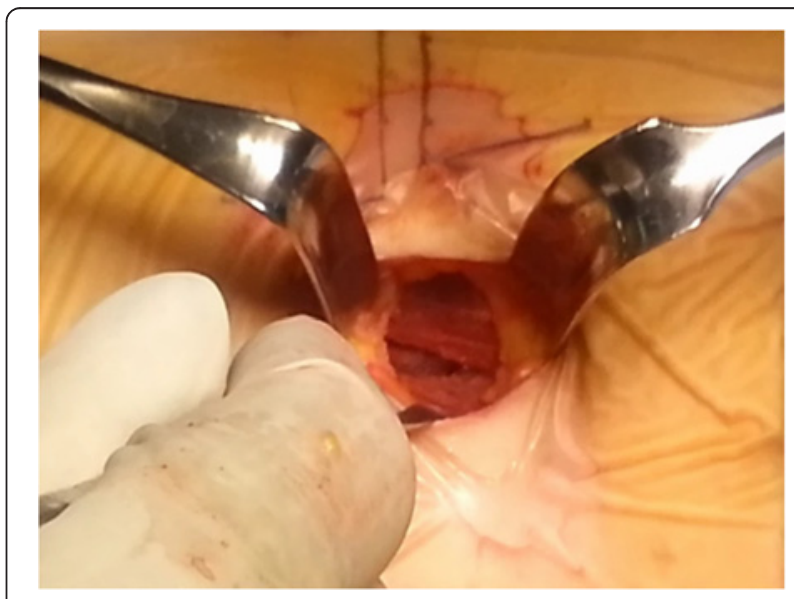

Fig. 1 A 2.5-3.0-cm skin incision was made centered in projection of the target segment and parallel to external oblique muscle fibers 


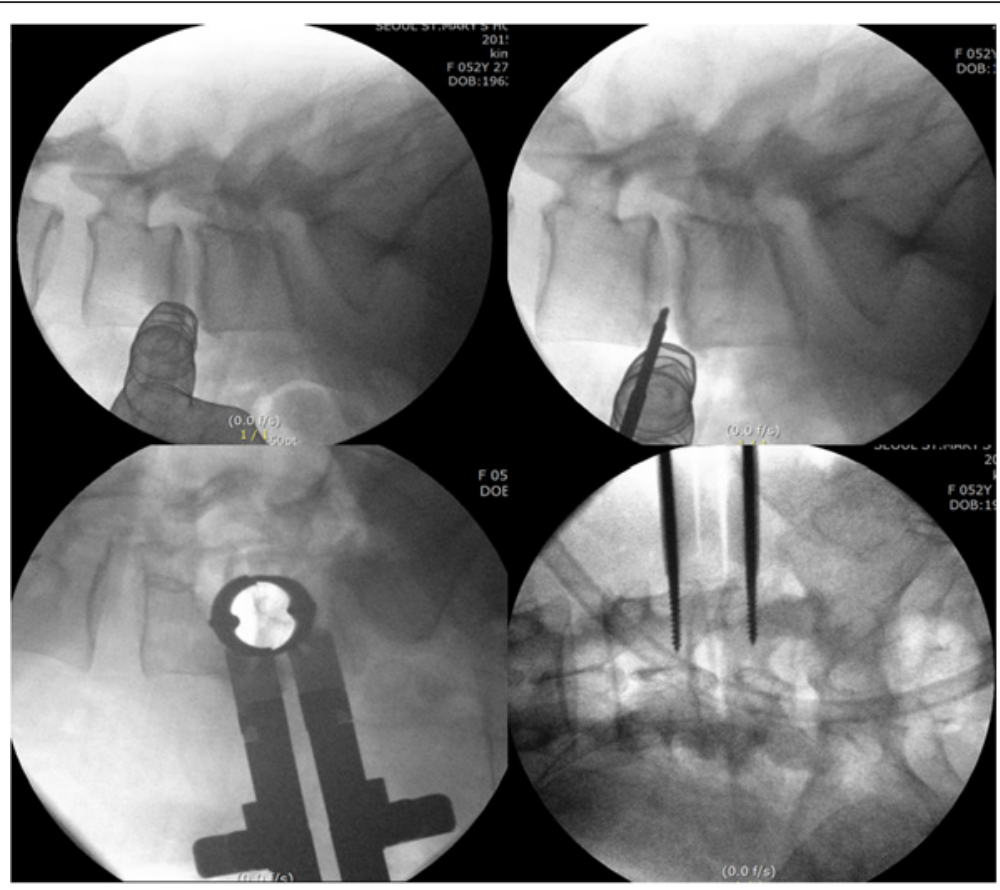

Fig. 2 The psoas muscle was dissected with the index finger, and tubular retractor system was docked in the targeting disc level

(ODI) score. These scores were calculated before surgery and postoperatively at 3 months, 6 months, 1 year, 2 years, and the final follow-up visit. Patient satisfaction rate (PSR), return to daily activity, and surgical recommendation to others were evaluated at every follow-up visit. About the assessment of PSR, return to daily activity, and surgical recommendation to others was according to interview of patients at every follow-up periods.

\section{Assessment of radiological outcomes}

Routine conventional X-ray images were obtained before surgery, immediately after the operation, and at

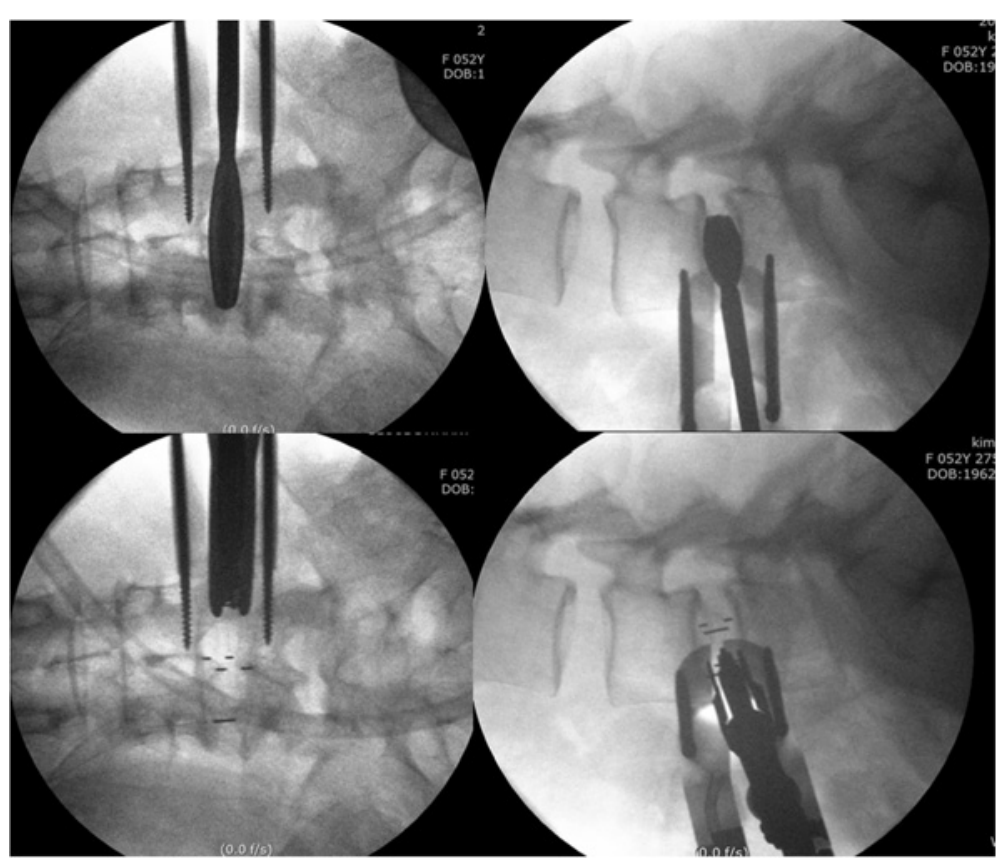

Fig. 3 Vertebral endplates were prepared, and cage packed with graft bone was inserted to the disc space 


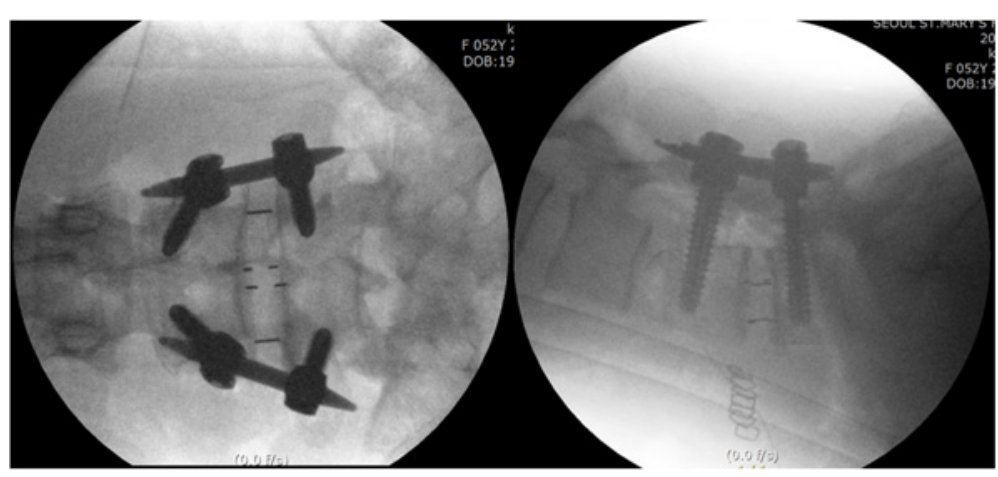

Fig. 4 Posterior pedicle screw fixation was performed using percutaneous approach

the final follow-up visit. Disc height was measured at the midpoint of the disc space on plain standing lateral radiography. The segmental lordotic angle was measured between the upper endplate of the cranial side of the vertebral body and the lower endplate of the caudal side of the vertebral body for the operating level (Fig. 5a) [15]. The lumbar lordotic angle was measured between the upper endplate of the L1 vertebral body and the upper endplate of the S1 vertebral body (Fig. 5b) [15]. Computed tomography (CT) images were obtained before surgery and postoperatively at 6 months, 1 year, 2 years, and at the final follow-up visit. Fusion status was analyzed using modified Bridwell fusion criteria $[16,17]$.

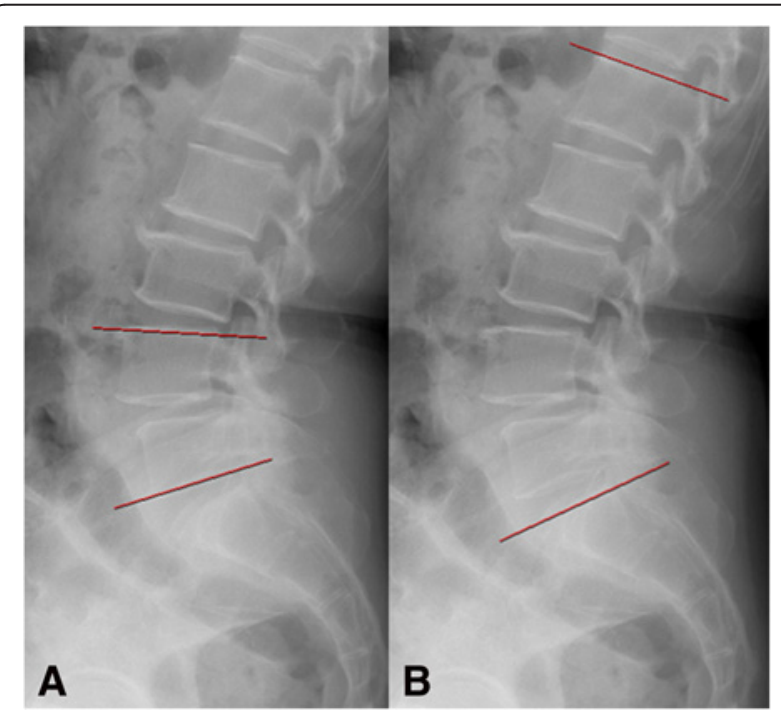

Fig. 5 a. The segmental lordotic angle was measured between the upper endplate of the cranial side of the vertebral body and the lower endplate of the caudal side of the vertebral body for the operating level. b. The lumbar lordotic angle was measured between the upper endplate of the $L 1$ vertebral body and the upper endplate of the S1 vertebral body

\section{Statistical analysis}

Different parameters measured between the two age groups were assessed with $t$ test for continuous variables and chi-square test or Fisher exact test for categorical variables. Data are presented as $n$ (\%) for categorical variables and mean \pm standard deviation $(\mathrm{SD})$ for continuous variables. All statistical analyses were performed using Statistical Analysis System (SAS) Version 9.4 (SAS Institute, Cary, NC, USA). Statistical significance was considered when the $p$ value was less than 0.05 .

\section{Results}

\section{Patient characteristics}

A total of 63 patients underwent OLIF procedure. The mean age of these patients was 67.1 years (range, 4985 years). Demographic data of group A and group B are summarized in Table 1 . There were statistically significant differences in age and bone mineral density (BMD) between the two groups. The mean hospital stay of all patients was 7.6 days (range, 3-24 days). Their mean operation time was $128.0 \mathrm{~min}$ (range, 55-325 min). Twelve patients ( 1 patient in group A, 6 patients in group B) needed the intraoperative transfusion. The mean blood transfusion volume was $29.8 \mathrm{ml}$ (range, $0-400 \mathrm{ml}$ ). The mean follow-up duration was 20.4 months (range, 1242 months). Preoperative diagnoses were degenerative spondylolisthesis (51.72\% in group A and $52.94 \%$ in group B), lumbar stenosis $(37.93 \%$ in group A and $38.24 \%$ in group B), and HNP (10.35\% in group A and $8.82 \%$ in group B). Perioperative data of group A and group B are summarized in Table 2. However, based on our limited number of cases, even though there was no statistically significant difference in perioperative parameters between two groups, no difference might not guarantee the equal clinical outcomes between two groups.

\section{Clinical outcomes}

The most common co-morbidity was cardiovascular problem $(38 / 63,60.31 \%)$ such as hypertensive disorder 
Table 1 Demographics characteristics of patients under or over 65 years of age

\begin{tabular}{llll}
\hline & $\leq 65$ (group A) & $>65$ (group B) & $p$ value \\
\hline Mean age: years (range) & $60.1 \pm 4.2(49.0-65.0)$ & $73.0 \pm 4.6(66.0-85.0)$ & $<0.0001^{\mathrm{a}}$ \\
Male/female: ratio & $10: 19$ & $15: 19$ & 0.4359 \\
Mean BMD: T-score (range) & $-1.2 \pm 1.4(-3.8-1.5)$ & $-2.0 \pm 1.6(-4.7-1.2)$ & $0.0416^{\mathrm{a}}$ \\
BMD $\leq-3.0$ : patients & 3 & 13 & $0.0112^{\mathrm{a}}$ \\
\hline
\end{tabular}

$B M D$ bone mineral density

${ }^{\mathrm{a}}$ Statistical significance was considered when the $p$ value was less than 0.05

(Table 3), followed by endocrinology disease (35/63, $55.56 \%)$. There were 17 patients with diabetes and 9 patients with rheumatoid arthritis. Results for the number of co-morbidities in the two age groups are summarized in Table 4. The mean NRS score for back pain was significantly decreased from 4.6 (range, 1.0-9.0) preoperatively to 2.3 (range, $0.0-7.0$ ) at the final follow-up visit in group A. It was decreased from 4.5 (range, $0.0-$ 8.0) preoperatively to 2.6 (range, $0.0-8.0$ ) at the final follow-up visit in group B. The NRS score for leg pain was decreased from 5.9 (range, 2.0-10.0) preoperatively to 1.8 (range, $0.0-6.0$ ) at the final follow-up visit in group A and from 6.8 (range, 2.0-9.0) preoperatively to 2.2 (range, $0.0-8.0$ ) at the final follow-up visit in group B. The ODI score was decreased from $48.4 \%$ (range, $32.0-68.0 \%$ ) preoperatively to $24.0 \%$ (range, $9.0-56.0 \%$ ) at the final follow-up visit in group A and from $46.5 \%$ (range, 30.0-70.0\%) preoperatively to $25.2 \%$ (range, 6.0$66.0 \%$ ) at the final follow-up visit in group B. Detailed changes in NRS and ODI scores from preoperatively to the final follow-up visit of the two age groups are shown in Figs. 6 and 7. During the follow-up period, one patient in group A had an additional surgery due to the development of an adjacent segment disease. One patient in group B died during the follow-up period. The PSR, return to daily activity, and surgical recommendation to others in group A and group B are summarized in Table 5.

\section{Radiological outcomes}

The average fusion level of the 63 patients was 1.5 (range, 1-3 levels). Detailed results of fusion level in the two age groups are summarized in Tables 6 and 7. Based on modified Bridwell fusion criteria, grade A fusion rates at 1-year, 2-year, and the final follow-up visits in group A were 13,80 , and $63 \%$, respectively, and grade B fusion rates were 80,20 , and $37 \%$, respectively. In group $\mathrm{B}$, grade $\mathrm{A}$ fusion rates at 1-year, 2-year, and the final follow-up visits were 37,91 , and $100 \%$, respectively, while grade B fusion rates were 57,9 , and $0 \%$, respectively (Table 8). Overall fusion rates at 1-year, 2 -year, and the final follow-up visits were 93,100 , and $100 \%$ in group A, 94,100 , and $100 \%$ in group B.

Disc height in group A was increased from $8.6 \mathrm{~mm}$ (range, $0.0-16.6 \mathrm{~mm}$ ) preoperatively to $13.4 \mathrm{~mm}$ (range, 10.6-17.0 $\mathrm{mm}$ ) postoperatively. At the final follow-up visit, disc height was decreased to $12.3 \mathrm{~mm}$ (range, 8.5-16.4 mm). Disc height in group B was increased from $8.9 \mathrm{~mm}$ (range, 2.9-17.4 mm) preoperatively to $13.9 \mathrm{~mm}$ (range, $9.0-18.9 \mathrm{~mm}$ ) postoperatively. At the final follow-up visit, disc height was decreased to $12.9 \mathrm{~mm}$ (range, 5.6-16.2 $\mathrm{mm}$ ) (Table 9). The segmental lordotic angle of the operating level in group A was increased from $10.1^{\circ}$ (range, - $16.4^{\circ}-$ $25.1^{\circ}$ ) preoperatively to $15.2^{\circ}$ (range, $1.5^{\circ}-28.2^{\circ}$ ) postoperatively. At the final follow-up visit, the angle was decreased to $14.9^{\circ}$ (range, $1.5^{\circ}-28.0^{\circ}$ ). In group $\mathrm{B}$, the segmental lordotic angle of the operating level was increased from $9.4^{\circ}$ (range, $-0.3^{\circ}-24.6^{\circ}$ ) preoperatively to $14.9^{\circ}$ (range, $0.1^{\circ}-27.8^{\circ}$ ) postoperatively. At the final follow-up visit, the angle was decreased to $14.2^{\circ}$ (range, $0.8^{\circ}-32.6^{\circ}$ ) (Table 9). The lumbar lordotic angle in group A was increased from $37.0^{\circ}$ (range, $5.6^{\circ}-56.5^{\circ}$ ) preoperatively to $42.5^{\circ}$ (range, $24.3^{\circ}-64.8^{\circ}$ )

Table 2 Perioperative data of patients under or over 65 years of age

\begin{tabular}{llll}
\hline & $\leq 65$ (group A) & $>65$ (group B) & $p$ value \\
\hline Hospital stay: day (range) & $6.8 \pm 6.6(3.0-20.0)$ & $8.2 \pm 8.4(3.0-24.0)$ & 0.1428 \\
Anesthesia time: minute (range) & $303.3 \pm 102.2$ & $337.2 \pm 115.8$ & $(170.0-710.0)$ \\
& $(185.0-600.0)$ & $132.5 \pm 113.8(55.0-325.0)$ & 0.2262 \\
Operation time: minutes (range) & $122.0 \pm 97.0(60.0-250.0)$ & $225.3 \pm 120.7(30.0-500.0)$ & 0.3721 \\
Intraoperative blood loss: $\mathrm{ml}$ (range) & $253.4 \pm 120.7(50.0-700.0)$ & $44.1 \pm 9.4(0.0-400.0)$ & 0.6103 \\
Blood transfusion: $\mathrm{ml}$ (range) & $13.1 \pm 7.8(0.0-380.0)$ & $18.5 \pm 9.3(12.0-37.0)$ & 0.4179 \\
Mean follow-up: months (range) & $22.8 \pm 11.2(12.0-42.0)$ & $1.5 \pm 0.7(1-3)$ & 0.5134 \\
Mean fusion level: number (range) & $1.5 \pm 0.8(1-3)$ & & 0.7988 \\
\hline
\end{tabular}


Table 3 Classification of co-morbidities

\begin{tabular}{lll}
\hline & Number of patients & Percentage \\
\hline Cardiovascular & 38 & 60.31 \\
Endocrinologic & 35 & 55.56 \\
Pulmonary & 4 & 6.35 \\
Hepatobiliary & 4 & 6.35 \\
Cerebrovascular & 3 & 4.76 \\
Urologic & 3 & 4.76 \\
Gastrointestinal & 1 & 1.59 \\
History of cancer & 4 & 6.34 \\
\hline
\end{tabular}

postoperatively. At the final follow-up visit, the angle was increased to $41.9^{\circ}$ (range, $25.3^{\circ}-63.7^{\circ}$ ). The lumbar lordotic angle in group B was increased from $38.3^{\circ}$ (range, $17.3^{\circ}-59.9^{\circ}$ ) preoperatively to $43.8^{\circ}$ (range, $\left.24.4^{\circ}-57.2^{\circ}\right)$ postoperatively. At the final follow-up visit, the angle was decreased to $42.4^{\circ}$ (range, $0.1^{\circ}-57.9^{\circ}$ ) (Table 9).

\section{Complications}

Overall perioperative complications occurred in 8 of 29 (27.6\%) patients in group A and in 10 of 34 (29.4\%) patients in group B. In group A, the isolated approachrelated complication occurred in 8 of 29 (27.6\%) patients while isolated approach-non-related complication occurred in 0 of $29(0 \%)$ patients. In group B, the isolated approach-related complication occurred in 9 of 34 (26.5\%) patients; isolated approach-non-related complication occurred in 1 of 34 (2.9\%) patients. Statistical analysis results of complications of group A and group B are summarized in Table 10. Lumbar plexopathy was the most common approach-related complication (5 patients in group A, 6 patients in group B). All 11 patients were treated with conservative care, of which 10 gradually recovered within 3- to 6-month period while one patient had persistent left hip flexion weakness (grade $4+$ at the final follow-up) but without any functional disability. Sympathetic chain symptoms were observed in 3 patients in group A and 1 patient in group B. Of the four patients, 3

Table 4 The number of co-morbidities in patients under or over 65 years of age

\begin{tabular}{llll}
\hline $\begin{array}{l}\text { Number of co-morbidities } \\
\text { in each patient }\end{array}$ & $\leq 65$ (group A) & $>65$ (group B) & $p$ value \\
\hline 0 & $8(27.59 \%)$ & $3(8.82 \%)$ & $0.0317^{\mathrm{a}}$ \\
1 & $9(31.03 \%)$ & $10(29.41 \%)$ & 0.8185 \\
2 & $6(20.69 \%)$ & $13(38.24 \%)$ & $0.0483^{\mathrm{a}}$ \\
3 & $5(17.24 \%)$ & $4(11.76 \%)$ & 0.7389 \\
4 & $1(3.45 \%)$ & $3(8.82 \%)$ & 0.0573 \\
5 & $0(0 \%)$ & $1(2.94 \%)$ & - \\
\hline
\end{tabular}

${ }^{\mathrm{a}}$ Statistical significance was considered when the $p$ value was less than 0.05

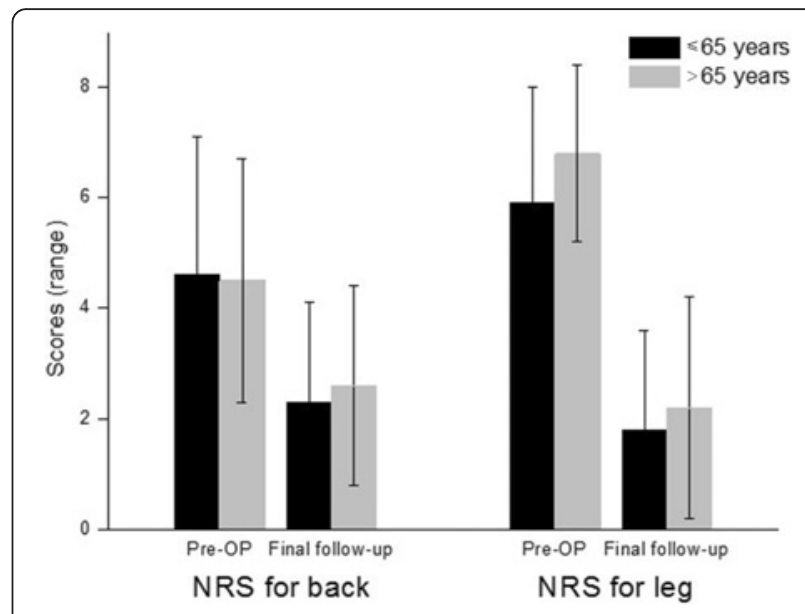

Fig. 6 Changes of NRS score in group A and group B during the follow-up period

gradually recovered within 2- to 4-month period. In the other one patient, symptoms persisted beyond 6 months. One patient had the intraoperative ventral dural tear which was treated with dural repair [18]. One patient had the intraoperative urethral injury which was treated with repair immediately by a urology surgeon [19]. The most common approach-non-related complication was postoperative respiratory complication. These were successfully treated with conservative treatment (Table 11). Fortunately, we do not have any fatal complications in these two groups enrolled.

\section{Discussion}

With increasing lifespan, the number of patients in need of fusion surgery is also increasing. High rates of postoperative morbidity and mortality have been reported [20, 21]. Based on reported in the literature, patients aged more than 65 years have higher rates of

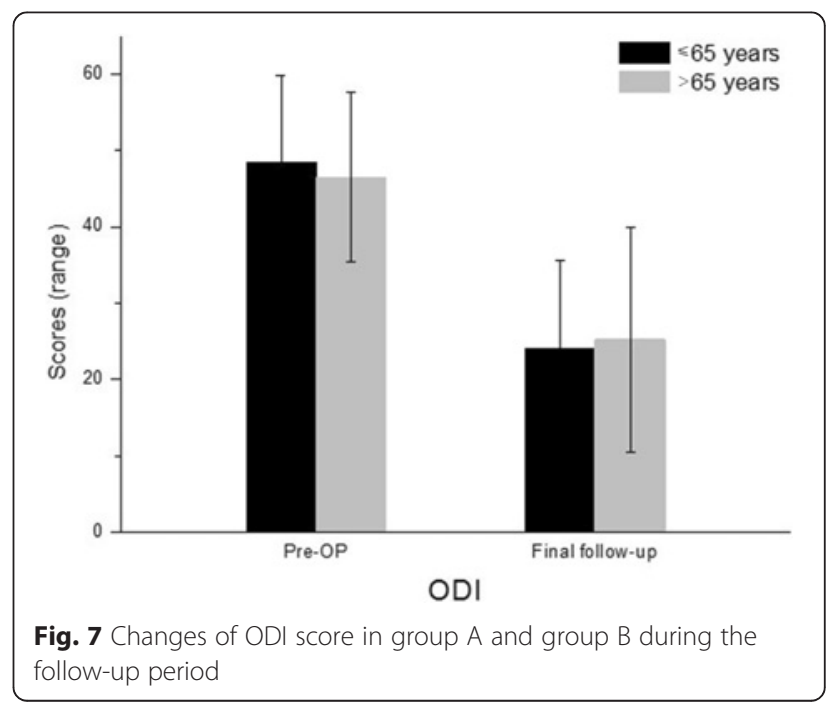


Table 5 PSR, return to daily activity, and surgical recommendation to others

\begin{tabular}{llll}
\hline & $\leq 65$ (group A) & $>65$ (group B) & $p$ value \\
\hline $\begin{array}{l}\text { PSR: score } \\
\text { (range) }\end{array}$ & $82.2 \pm 15.1$ & $79.6 \pm 13.1$ & 0.5205 \\
$\begin{array}{l}\text { Return to } \\
\text { daily activity }\end{array}$ & $92.00 \%$ & $(50.0-100.0)$ & \\
$\begin{array}{l}\text { Surgical } \\
\text { recommendation } \\
\text { to others }\end{array}$ & $88.00 \%$ & $95.83 \%$ & 1.0000 \\
\hline
\end{tabular}

PSR patient's satisfaction rate

major complications $[22,23]$. These increased rates of morbidity and mortality reflect that the number of systemic diseases and operative blood loss are increased and hospital stay is longer [24].

Traditional posterior lumbar interbody fusion can cause unavoidable damage to paraspinal back muscles, soft tissue, and posterior bone structure of the lumbar spine. Moreover, it can expose neural elements in the spinal canal to iatrogenic injury. In the last few decades, many surgeons have explored various surgical approaches, especially focusing on minimally invasive techniques, to achieve lumbar fusion while avoiding complications caused by posterior lumbar interbody fusion.

ALIF provides direct access to the intervertebral disc. It allows easy removal of disc and implant insertion with the excellent restoration of disc height and optimal correction of sagittal balance, thus reducing the incidence of ASD with relative preservation of spine anatomy [25-28]. However, ALIF can potentially cause vessel injury due to retraction [29]. An anterolateral and minimally invasive approach was introduced by Mayer in 1997 [3]. It was then modified by McAfee et al. [30] and Ozgur et al. [7] into a trans-muscular, psoas-splitting access, and extreme lateral trans-psoas approach for interbody fusion (XLIF). However, the XLIF approach has risks of causing neurologic injuries while dissecting the psoas muscle [31].

"Oblique lateral interbody fusion" or OLIF was introduced in 2012 [11]. This new approach reflects a paradigm shift in anterolateral spinal fusion surgery. It is a solution to the caveats of both ALIF and LLIF techniques [25, 32-35].

The largest cohort study up to date has described the outcome of the OLIF procedure [11]. From a cohort of 179 patients, 19 (10.6\%) developed the single

Table 6 Results of fusion level

\begin{tabular}{llll}
\hline Number of level & $\leq 65($ group A) & $>65($ group B) & $p$ value \\
\hline Total & 44 & 50 & 0.4041 \\
1 level & 19 & 21 & 0.7518 \\
2 levels & 5 & 10 & 0.1967 \\
3 levels & 5 & 3 & 0.4795 \\
\hline
\end{tabular}

Table 7 Results of fusion level site

\begin{tabular}{llll}
\hline Level site & $\leq 65($ group A) & $>65($ group B) & $p$ value \\
\hline L2-3 & 6 & 9 & 0.4386 \\
L3-4 & 12 & 23 & 0.0630 \\
L4-5 & 25 & 18 & 0.2278 \\
\hline
\end{tabular}

complication, while one individual had two complications. These complications were incisional pain (2.2\%), sympathetic chain injury (1.7\%), vascular injury to iliac and iliolumbar vessels (1.7\%), neurological deficits (2 patients), and symptomatic L5-S1 pseudoarthrosis (1 patient), which were comparable to traditional approaches. Overall, this relatively large cohort study has demonstrated the feasibility of using anterolateral access for fusion of the lumbar spine. However, that study used a mini-open technique. Compared to that study, we demonstrated a further minimally invasive OLIF technique aided by tubular retractor system. Another study based on a nationwide survey in Japan [36] demonstrated that compared with extreme lateral trans-psoas interbody fusion, OLIF procedure can effectively reduce the incidence of related complications.

We included 63 patients in our study. The overall complication rate was $28.6 \%$, which was $27.6 \%$ in patients under 65 years and $29.4 \%$ in those over 65 years of age. The most common approach-related complication was lumbar plexopathy (17.5\%). Sensory lumbar plexopathy including left inguinal symptoms and left anterior thigh numbness was seen in 5 patients in group A and 4 patients in group B. All patients had transient symptoms. Motor lumbar plexopathy in the form of left hip flexion weakness was seen in 2 patients in group B. One patient was rapidly improved whereas the other patient had persistent weakness without functional debilitation at the final follow-up. Sympathetic chain symptoms were observed in 3 patients in group A and 1 patient in group B. Of the four patients, 3 gradually recovered within 2- to 4-month period. In the other one patient, symptoms persisted beyond 6 months. During the operation of OLIF, sympathetic chain symptoms could be injured because the position of sympathetic chain overlaps with OLIF corridor and surgeons need gentle

Table 8 Fusion rates during follow-up period

\begin{tabular}{lllllll}
\hline $\begin{array}{l}\text { Follow-up } \\
\text { period }\end{array}$ & $\begin{array}{l}\text { Fusion } \\
\text { grade }\end{array}$ & $\leq 65$ (group A) & $>65$ (group B) & $p$ value \\
\hline 1 year & Grade A & $n=27 / 29$ & $13 \%$ & $n=32 / 34$ & $37 \%$ & 0.4812 \\
& Grade B & & $80 \%$ & & $57 \%$ & \\
2 years & Grade A & $n=23 / 23$ & $80 \%$ & $n=24 / 24$ & $91 \%$ & 0.4072 \\
& Grade B & & $20 \%$ & & $9 \%$ & \\
$>2$ years & Grade A & $n=7 / 7$ & $63 \%$ & $n=2 / 2$ & $100 \%$ & 1.0000 \\
& Grade B & & $37 \%$ & & $0 \%$ & \\
\hline
\end{tabular}


Table 9 Changes in disc height, segmental lordotic angle, and lumbar lordotic angle

\begin{tabular}{|c|c|c|c|c|}
\hline & & $\leq 65(\operatorname{group} A)$ & $>65$ (group B) & $p$ value \\
\hline \multirow[t]{3}{*}{ Disc height: mm (range) } & Pre-OP & $8.6 \pm 2.9(0.0-16.6)$ & $8.9 \pm 3.0(2.9-14.7)$ & 0.5327 \\
\hline & Post-OP & $13.4 \pm 1.8(10.6-17.0)$ & $13.9 \pm 2.4(9.0-18.9)$ & 0.2196 \\
\hline & Final follow-up & $12.3 \pm 1.7(8.5-16.4)$ & $12.9 \pm 2.1(5.6-16.2)$ & 0.6108 \\
\hline \multirow[t]{3}{*}{ Segmental lordotic angle: degree (range) } & Pre-OP & $10.1 \pm 7.8(-16.4-25.1)$ & $9.4 \pm 6.3(-0.3-24.6)$ & 0.6590 \\
\hline & Post-OP & $15.2 \pm 6.2(1.5-28.2)$ & $14.9 \pm 6.0(0.1-27.8)$ & 0.0703 \\
\hline & Final follow-up & $14.9 \pm 6.4(1.5-28.0)$ & $14.2 \pm 6.2(0.8-32.6)$ & 0.1645 \\
\hline \multirow[t]{3}{*}{ Lumbar lordotic angle: degree (range) } & Pre-OP & $37.0 \pm 12.2(5.6-56.5)$ & $38.3 \pm 11.8(17.3-59.9)$ & 0.6633 \\
\hline & Post-OP & $42.5 \pm 9.9(24.3-64.8)$ & $43.8 \pm 8.5(24.4-57.2)$ & 0.3159 \\
\hline & Final follow-up & $41.9 \pm 9.4(25.3-63.7)$ & $42.4 \pm 13.1(0.1-57.9)$ & 0.3059 \\
\hline
\end{tabular}

OP operation

dissection of the psoas muscles. But most complicated cases are transient and minor, and most of them improve themselves within 3 to 6 months after the operation. This complication was also reported after ALIF procedure [37]. In our study, the incidence of major complications, such as ureteral injury, vascular injury, and ventral dural damage, was only $3 \%$ ( $0 \%$ in group A, $3 \%$ in group B). No vascular injury was reported in both groups. In the elderly group, one patient reported intraoperative ventral dural damage [18] while another reported intraoperative ureteral injury [19]. In order to avoid any kind of injury on ventral dura mater, we recommend that the surgeon has to evaluate the proper OLIF angle before surgery and check intraoperative $\mathrm{C}$-arm images frequently. To avoid the ureter injury, we also recommend using the tip of one's finger to find the direction of the disc space and to dissect psoas muscle. In contrast to a surgical device, the fingertip is blunt and can feel the track of ureter. Although the complication rate of the elder group was slightly higher than that of the younger group, there was no significant difference in clinical outcome between the two groups based on clinical outcomes, patient's satisfaction rate, and willingness to recommend it to others. However, based on our limited number of cases, even though there was no statistically significant difference in perioperative parameters between two groups, no difference might not guarantee the equal clinical outcomes between the two groups.

One of the major reasons for complications in spine fusion surgery is the higher frequency of co-morbidities in elderly patients. In our study, $82.5 \%(52 / 63)$ of

Table 10 Complications in patients under or over 65 years of age

\begin{tabular}{llll}
\hline Complications & $\leq 65$ (group A) & $>65$ (group B) & $p$ value \\
\hline Total & $n=8(27.6 \%)$ & $n=10(29.4 \%)$ & 0.4339 \\
$\begin{array}{l}\text { Approach-related } \\
\text { complication }\end{array}$ & $n=8(27.6 \%)$ & $n=9(26.5 \%)$ & 0.7389 \\
$\begin{array}{l}\text { Approach-non-related } \\
\text { complication }\end{array}$ & $n=0(0 \%)$ & $n=1(2.9 \%)$ & - \\
\hline
\end{tabular}

patients had co-morbidities $(72.4 \%$ in those under 65 years of age and $91.2 \%$ in those over 65 years of age). The most common co-morbidity was cardiovascular. Another major co-morbidity was diabetes. Many of these patients were on anti-platelets (or anti-coagulants) such as aspirin and clopidogrel. These drugs might increase the risk of perioperative bleeding. Osteoporosis is believed to be a risk factor for subsidence, screw loosening, and fusion failure [38-40]. In our study, the average Tscore change on DEXA scan was -1.2 in those under 65 years of age and -1.9 in those over 65 years of age. During the perioperative period, $21 \%$ of patients who were under 65 years of age and $47 \%$ of patients of those who were over 65 years of age were treated with osteoporosis medication. In our study, one patient who was treated with conservative treatment had postoperative adjacent level lumbar vertebral compression fracture in group B. Subsidence occurred in $12(27.3 \%)$ of 44 levels at 6 months and 1 year after surgery in group A.

Table 11 Classification of complications

\begin{tabular}{lll}
\hline Complications & $\leq 65$ (group A) & $>65$ (group B) \\
\hline Approach-related complication & 0 & 0 \\
Abdominal vascular injury & 0 & 1 \\
Ventral dural tear & 0 & 1 \\
Ureteral injury & 5 & 4 \\
Lumbar plexopathy (sensory) & 0 & 2 \\
Lumbar plexopathy (motor) & 0 & 1 \\
Sympathetic chain symptom & 3 & 0 \\
Screw malposition & 0 & 0 \\
Wound infection & 0 & 0 \\
Ileus & 0 & 0 \\
Approach-non-related complication & & 1 \\
Urinary system complication & 0 & 0 \\
Respiratory complication & 0 & 0 \\
Delirium & 0 & \\
\hline
\end{tabular}


However, subsidence occurred in 19 (38\%) of 50 levels at 6 months after surgery and $22(40 \%)$ of 50 levels at 1 year after surgery in group B. There was no revision surgery related to subsidence of cage. Symptomatic pseudoarthrosis was not observed during the follow-up period in either group.

In our study, the segmental lordotic angle and the lumbar lordotic angle were increased immediately after the surgery. However, it was decreased in both groups as time went by. After a follow-up time of at least 1 year, significant clinical improvement in segmental lordotic angle and lumbar lordotic angle were observed in both group A and group B.

Our study had several limitations. First, it had a retrospective study design with a small sample size. In addition, the duration of follow-up was relatively short. Further follow-up is needed to strengthen these observations. In addition, a larger number of patients should be enrolled in future studies to confirm our findings.

\section{Conclusion}

In this study, patients over 65 years of age had the slightly high incidence of complication compared with those younger than 65 years. However, based on clinical outcomes, patient's satisfaction rate, and willingness to recommend it to others, OLIF in elderly patients also showed satisfactory clinical and radiological outcomes; OLIF may be considered as an alternative surgical method for degenerative spinal disease in the elder population.

\begin{abstract}
Abbreviations
ALIF: Anterior lumbar interbody fusion; ASD: Adjacent segment disease; BMD: Bone mineral density; CT: Computed tomography; DBM: Demineralized bone matrix; DDD: Degenerative disc disease; HNP: Herniated nucleus pulposus; IRB: Institutional review board; LLIF: Lateral lumbar interbody fusion; MIS: Minimally invasive spinal; NC: North Carolina; NRS: Numeric Rating Scale; ODI: Oswestry disability index; OLIF: Oblique lateral interbody fusion; OP: Operation; PLIF: Posterior lumbar interbody fusion; PSR: Patient's satisfaction rate; SAS: Statistical Analysis System; SD: Standard deviation; TLIF: Transforaminal lumbar interbody fusion; USA: United States of America; XLIF: Extreme lateral trans-psoas approach for interbody fusion
\end{abstract}

\section{Acknowledgements}

The authors wish to acknowledge the financial support of the Catholic Medical Center Research Foundation made in the program year of 2016.

\section{Funding}

Not applicable

\section{Availability of data and materials}

The datasets used and/or analyzed during the current study are available from the corresponding author on reasonable request.

\section{Authors' contributions}

CJ made substantial contributions to the conception and design, or acquisition of data, or analysis and interpretation of data. MSJ involved in drafting the manuscript or revising it critically for important intellectual content. SSJ has given final approval of the version to be published. KSR agreed to be accountable for all aspects of the work in ensuring that questions related to the accuracy or integrity of any part of the work are appropriately investigated and resolved. JWH involved in drafting the manuscript or revising it critically for important intellectual content. JSK made substantial contributions to the conception and design, or acquisition of data, or analysis and interpretation of data and has given final approval of the version to be published. All authors read and approved the final manuscript.

\section{Ethics approval and consent to participate}

Our study was approved by the institutional review board (IRB) of Seoul St. Mary's Hospital, College of Medicine, The Catholic University of Korea.

\section{Consent for publication}

All volunteers agreed to participate in research and consent for publication.

\section{Competing interests}

The authors declare that they have no competing interests.

\section{Publisher's Note}

Springer Nature remains neutral with regard to jurisdictional claims in published maps and institutional affiliations.

Received: 26 December 2017 Accepted: 5 February 2018

Published online: 20 February 2018

References

1. Assaker R. Minimal access spinal technologies: state-of-the-art, indications, and techniques. Joint Bone Spine. 2004:71:459-69.

2. Mobbs RJ, Phan K, Malham G, Seex K, Rao PJ. Lumbar interbody fusion: techniques, indications and comparison of interbody fusion options including PLIF, TLLF, MI-TLIF, OLIF/ATP, LLIF and ALIF. J Spine Surg. 2015;1:2-18.

3. Mayer HM. A new microsurgical technique for minimally invasive anterior lumbar interbody fusion. Spine. 1997;22:691-9. discussion 700

4. Harms J, Rolinger H. A one-stager procedure in operative treatment of spondylolistheses: dorsal traction-reposition and anterior fusion (author's transl). Z Orthop Ihre Grenzgeb. 1982;120:343-7.

5. Lestini WF, Fulghum JS, Whitehurst LA. Lumbar spinal fusion: advantages of posterior lumbar interbody fusion. Surg Technol Int. 1994;3:577-90.

6. Cole CD, McCall TD, Schmidt MH, Dailey AT. Comparison of low back fusion techniques: transforaminal lumbar interbody fusion (TLIF) or posterior lumbar interbody fusion (PLIF) approaches. Curr Rev Musculoskelet Med. 2009;2:118-26.

7. Ozgur BM, Aryan HE, Pimenta L, Taylor WR. Extreme lateral interbody fusion (XLIF): a novel surgical technique for anterior lumbar interbody fusion. Spine J. 2006;6:435-43.

8. Arnold PM, Anderson KK, McGuire RA Jr. The lateral transpsoas approach to the lumbar and thoracic spine: a review. Surg Neurol Int. 2012;3:S198-215.

9. Lee YS, Kim YB, Park SW, Chung C. Comparison of transforaminal lumbar interbody fusion with direct lumbar interbody fusion: clinical and radiological results. J Korean Neurosurg Soc. 2014;56:469-74.

10. Phan K, Maharaj M, Assem Y, Mobbs RJ. Review of early clinical results and complications associated with oblique lumbar interbody fusion (OLIF). J Clin Neurosci. 2016;31:23-9.

11. Silvestre C, Mac-Thiong JM, Hilmi R, Roussouly P. Complications and morbidities of mini-open anterior retroperitoneal lumbar interbody fusion: oblique lumbar interbody fusion in 179 patients. Asian Spine J. 2012;6:89-97.

12. Molinares DM, Davis TT, Fung DA. Retroperitoneal oblique corridor to the L2-S1 intervertebral discs: an MRI study. J Neurosurg Spine. 2015:1-8.

13. Lin GX, Quillo-Olvera J, Jo HJ, Lee HJ, Covarrubias-Rosas CA, Jin C, et al. Minimally invasive transforaminal lumbar interbody fusion: a comparison study based on end plate subsidence and cystic change in individuals older and younger than 65 years. World Neurosurg. 2017;106:174-84.

14. Jo DJ, Jun JK, Kim KT, Kim SM. Lumbar interbody fusion outcomes in degenerative lumbar disease: comparison of results between patients over and under 65 years of age. J Korean Neurosurg Soc. 2010;48:412-8.

15. Choi WS, Kim JS, Ryu KS, Hur JW, Seong JH. Minimally invasive transforaminal lumbar interbody fusion at L5-S1 through a unilateral approach: technical feasibility and outcomes. Biomed Res Int. 2016;2016: 2518394

16. Bridwell KH, Lenke LG, McEnery KW, Baldus C, Blanke K. Anterior fresh frozen structural allografts in the thoracic and lumbar spine. Do they work if combined with posterior fusion and instrumentation in adult patients with kyphosis or anterior column defects? Spine. 1995;20:1410-8. 
17. Bridwell $K H$, O'Brien MF, Lenke LG, Baldus C, Blanke K. Posterior spinal fusion supplemented with only allograft bone in paralytic scoliosis. Does it work? Spine. 1994;19:2658-66.

18. Chang J, Kim JS, Jo H. Ventral Dural Injury After Oblique Lumbar Interbody Fusion. World Neurosurg. 2016;98:881.e1-e4.

19. Lee HJ, Kim JS, Ryu KJ. Ureter Injury as a Complication of Oblique Lumbar Interbody Fusion. World Neurosurg. 2017;102:693.e7-e14.

20. Lee P, Fessler RG. Perioperative and postoperative complications of singlelevel minimally invasive transforaminal lumbar interbody fusion in elderly adults. J Clin Neurosci. 2012;19:111-4.

21. Carragee EJ. The increasing morbidity of elective spinal stenosis surgery: is it necessary? JAMA. 2010;303:1309-10.

22. Carreon LY, Puno RM, Dimar JR 2nd, Glassman SD, Johnson JR. Perioperative complications of posterior lumbar decompression and arthrodesis in older adults. J Bone Joint Surg Am. 2003;85-a:2089-92.

23. Daubs MD, Lenke LG, Cheh G, Stobbs G, Bridwell KH. Adult spinal deformity surgery: complications and outcomes in patients over age 60. Spine. 2007; 32:2238-44.

24. Park P, Foley KT. Minimally invasive transforaminal lumbar interbody fusion with reduction of spondylolisthesis: technique and outcomes after a minimum of 2 years' follow-up. Neurosurg Focus. 2008;25:E16.

25. Rao PJ, Loganathan A, Yeung V, Mobbs RJ. Outcomes of anterior lumbar interbody fusion surgery based on indication: a prospective study. Neurosurgery. 2015;76:7-23. discussion -4

26. Choi KC, Kim JS, Shim HK, Ahn Y, Lee SH. Changes in the adjacent segment 10 years after anterior lumbar interbody fusion for low-grade isthmic spondylolisthesis. Clin Orthop Relat Res. 2014;472:1845-54.

27. Kim JS, Choi WG, Lee SH. Minimally invasive anterior lumbar interbody fusion followed by percutaneous pedicle screw fixation for isthmic spondylolisthesis: minimum 5-year follow-up. Spine J. 2010;10:404-9.

28. Kim JS, Kang BU, Lee SH, Jung B, Choi YG, Jeon SH, et al. Minitransforaminal lumbar interbody fusion versus anterior lumbar interbody fusion augmented by percutaneous pedicle screw fixation: a comparison of surgical outcomes in adult low-grade isthmic spondylolisthesis. J Spinal Disord Tech. 2009;22:114-21.

29. Mobbs RJ, Phan K, Daly D, Rao PJ, Lennox A. Approach-related complications of anterior lumbar interbody fusion: results of a combined spine and vascular surgical team. Global Spine J. 2016:6:147-54.

30. MCAfee PC, Regan JJ, Geis WP, Fedder IL. Minimally invasive anterior retroperitoneal approach to the lumbar spine. Emphasis on the lateral BAK. Spine. 1998;23:1476-84.

31. Benglis DM, Vanni S, Levi AD. An anatomical study of the lumbosacral plexus as related to the minimally invasive transpsoas approach to the lumbar spine. J Neurosurg Spine. 2009;10:139-44.

32. Phan K, Thayaparan GK, Mobbs RJ. Anterior lumbar interbody fusion versus transforaminal lumbar interbody fusion - systematic review and metaanalysis. Br J Neurosurg. 2015;29:705-11.

33. Rao PJ, Ghent F, Phan K, Lee K, Reddy R, Mobbs RJ. Stand-alone anterior lumbar interbody fusion for treatment of degenerative spondylolisthesis. Clin Neurosci. 2015;22:1619-24.

34. Bergey DL, Villavicencio AT, Goldstein T, Regan JJ. Endoscopic lateral transpsoas approach to the lumbar spine. Spine. 2004;29:1681-8.

35. Cummock MD, Vanni S, Levi AD, Yu Y, Wang MY. An analysis of postoperative thigh symptoms after minimally invasive transpsoas lumbar interbody fusion. J Neurosurg Spine. 2011;15:11-8.

36. Fujibayashi S, Kawakami N, Asazuma T, Ito M, Mizutani J, Nagashima H, et al. Complications associated with lateral interbody fusion: nationwide survey of 2998 cases during the first two years of its use in Japan. Spine. 2017:42(19): $1478-84$.

37. Quraishi NA, Konig M, Booker SJ, Shafafy M, Boszczyk BM, Grevitt MP, et al. Access related complications in anterior lumbar surgery performed by spinal surgeons. Eur Spine J. 2013;22(Suppl 1):S16-20

38. Tempel ZJ, Gandhoke GS, Okonkwo DO, Kanter AS. Impaired bone mineral density as a predictor of graft subsidence following minimally invasive transpsoas lateral lumbar interbody fusion. Eur Spine J. 2015;24(Suppl 3):414-9.

39. Galbusera F, Volkheimer D, Reitmaier S, Berger-Roscher N, Kienle A, Wilke HJ. Pedicle screw loosening: a clinically relevant complication? Eur Spine J. 2015:24:1005-16

40. Chen F, Dai Z, Kang Y, Lv G, Keller ET, Jiang Y. Effects of zoledronic acid on bone fusion in osteoporotic patients after lumbar fusion. Osteoporos Int. 2016;27:1469-76.

\section{Submit your next manuscript to BioMed Central and we will help you at every step:}

- We accept pre-submission inquiries

- Our selector tool helps you to find the most relevant journal

- We provide round the clock customer support

- Convenient online submission

- Thorough peer review

- Inclusion in PubMed and all major indexing services

- Maximum visibility for your research

Submit your manuscript at www.biomedcentral.com/submit
Biomed Central 